\title{
LOCUS OF CONTROL DAN BUDAYA ORGANISASI TERHADAP KEPUASAN DAN KINERJA GURU
}

\author{
Hamzah $^{1}$, Miftah Syarif ${ }^{2}$, Mar Artur Rahima ${ }^{3}$, Astri Ayu Purwati ${ }^{4}$ \\ Universitas Islam Riau $^{1,2,3}$ Institut Bisnis dan Teknologi Pelita Indonesia ${ }^{4}$ \\ hamzah@fis.uir.ac.id ${ }^{1}$
}

\begin{abstract}
ABSTRAK
Penelitian ini bertujuan untuk menguji pengaruh locus of control dan budaya organisasi terhadap kepuasan kerja dan kinerja guru MTsN di Pekanbaru. Populasi dalam penelitian ini adalah Guru MTsN di Pekanbaru dan total sampel yang digunakan adalah sebanyak 111 orang guru. Metode analisa data yang digunakan adalah Structural Equation Model (SEM) dengan PLS. Hasil penelitian menunjukkan bahwa locus of control memiliki pengaruh positif signifikan terhadap kepuasan dan kinerja guru sedangkan budaya organisasi hanya memiliki pengaruh positif signifikan terhadap peningkatan kepuasan guru namun tidak pada kinerja guru. Selanjutnya kepuasan juga ditemukan tidak memberikan pengaruh signifikan terhadap kinerja guru.
\end{abstract}

Kata Kunci : Locus of Control, Budaya Organisasi, Kepuasan, Kinerja Guru

\begin{abstract}
This study aims to examine the effect of locus of control and organizational culture on improving job satisfaction and performance of MTsN teachers in Pekanbaru. The population in this study were MTsN teachers in Pekanbaru and the total sample used was 111 teachers. The data analysis technique used is the Structural Equation Model (SEM) with PLS. The results showed that Locus of control had a significant positive effect on teacher satisfaction and performance, while organizational culture only had a significant positive effect on increasing teacher satisfaction but not on teacher performance. Furthermore, satisfaction was also found to have no significant effect on the performance
\end{abstract}

Keywords: Locus of Control, Organizational Culture, Satisfaction, Teacher Performance

\section{PENDAHULUAN}

Madrasah merupakan suatu lembaga pendidikan formal yang berbasis keislaman dan memiliki fokus untuk mengajarkan kepada mahasiswa didik terkait pembentukan akidah dan pendekatan keagamaan. Pengelolaan madrasah membuhukan koordinasi yang tinggi serta sumber daya manusia yang berkualitas. Guru dan/atau tenaga pendidik merupakan unsur penting bagi sumber daya manusia suatu madrasah dimana guru dan tenaga pendidik memiliki fungsi interaksi dan interaktif dalam menghasilkan suatu proses pembelajaran dan pelayanan sekolah yang berkualitas. Maka dari itu, bagi menciptakan sumber daya manusia yang cerdas maka diperlukan lembaga pendidikan professional yang 
memiliki tenaga pendidik yang memiliki kinerja yang baik. Umam (2010) menyatakan kinerja merupakan hasil kerja atau pencapaian suaru individu sesuai dengan tugas dan fungsinya yang dapat di ukur dan di evaluasi setiap periode tertentu. Dalam hal madrasah dan sekolah, guru memiliki fungsi dan tugas untuk memberikan pelayanan pembelajaran mulai dari persiapan bahan pembelajaran, metode pembelajaran serta penciptaan proses belajar yang kondusif dan hasil pembelajaran yang maksimal. Selain itu, kinerja guru terutama guru madrasah sangat penting harus di tingkatkan demi mempertahankan eksitensi madrasah sebagai organisasi pendidikan yang berkualitas hingga mampu bersaing dengan organisasi pendidikan Negeri maupun swasta lainnya.

Menurut Shirly (2018) kepuasan kerja merupakan suatu sikap emosianal yang ditunjukkan melalui rasa senang dan cinta terhadap suatu pekerjaan. Perilaku ini biasa di cerminkan oleh suatu sikap disiplin, moral dalam bekerja dan prestasi dalam pencapaian hasil kerja. Seseorang yang memiliki kepuasan tinggi terhadap suatu pekerjaan akan menghasilkan perilaku-perilaku positif terutama untuk mencapai suatu pekerjaannya. Maka dari itu hal ini dapat di artikan bahwasanya karyawan dengan kepuasan kerja yang tinggi mampu mendorong sesorang untuk mencapai hasil kerja/kinerja yang baik. Penelitian terdahulu oleh Shirly (2018); Aulia et al. (2017) menunjukkan terdapat pengaruh positif signifikan antara kepuasan kerja terhadap kinerja karyawan. Namun hasil penelitian tersebut bertolak belakang dengan penelitian yang dilakukan oleh Kuswoyo, et al. (2018); Amalini, et al. (2016) kepuasan kerja tidak berpengaruh signifikan terhadap kinerja karyawan melainkan dipengaruh oleh faktor-faktor lainnya.

Selain kepuasan kerja, faktor lainnya yang mempengaruhi kinerja guru madrasah adalah locus of control. Dalam penelitian ini, peneliti menemukan pentingnya aspek locus of control yang harus di teliti dalam individu tenaga pengajar di madrasah, karena control diri merupakan poin penting dalam berinteraksi serta menyampaikan suatu pelayanan kepada orang lain terutama peserta didik. Hellriegel \& Slocum (2011) menyatakan locus of control adalah suatu kecenderungan suatu individu atau orang dalam memberikan tanggapan terhadap hal-hal yang berlaku dalam hidupnya, apakah hal tersebut berada dalam kontrol dirinya sendiri atau hal lain diluar dari dirinya. Locus of control terbagi atas dua jenis yaitu internal dan external.

Menurut Zulkaida (2007) seorang karyawan yang yakin terhadap kemampuan dirinya dalam menyelesaikan suatu masalah dan pekerjaan, akan menimbulkan perasaan puas dalam sebuah pekerjaannya dan cenderung membantu kepada peningkatan kinerja. Hasil penelitian Hermawan \& Kaban (2014); Amalini et al. (2016) locus of control memiliki pengaruh positif terhadap kinerja karyawan. Untuk pengaruhnya terhadap kepuasan kerja, Amalini, et al. (2016), Adi, et al. (2012); Nainggolan et al., (2018) berhasil membuktikan bahwa locus of control berpengaruh positif signifikan terhadap kepuasan kerja karyawan. Namun hasil penelitian mereka berbeda dengan yang dilakukan oleh Hastuti \& 
Farid (2015) locus of control tidak memiliki pengaruh signifikan dengan kepuasan kerja karyawan. Selanjutnya penelitian Putri (2015) menunjukkan bahwa karyawan yang memiliki locus of control yang tinggi akan lebih mudah puas terhadap pekerjaannya yang nantinya akan turut meningkatkan kinerja.

Selain kepuasan kerja dan locus of control, bagi memperoleh hasil kerja guru madrasah yang baik maka diperlukan guru yang memiliki sifat jujur pada pekerjaannya, setia terhadap organisasinya, penuh dedikasi, disiplin tinggi serta senantiasa menyadari akan tanggung jawab dan kewajibannya. Bagi memperoleh itu semua, organisasi madrasah harus mempersiapkan suatu budaya yang baik agar hal tersebut menjadi suatu kebiaasaan yang mampu menciptakan lingkungan kerja kondusif dalam hal meningkatkan kinerja guru dan tenaga pendidik. Menurut Husein (2010) budaya organisasi merupakan suatu falsafah nilai dan keyakinan dari suatu kebiasaan bersamayang kemudian menghasilkan normanorma sebagai pedoman perilaku/tindakan dan cara berfikir dalam upaya pencapaian tujuan bersama. Penelitian-penelitian terdahulu juga telah menemukan hubungan budaya organisasi dengan kinerja karyawan diantaranya Kusuma \& Rahardja (2018); Hasan (2017); Cahyono (2012); Arianty (2015) budaya organisasi memiliki pengaruh positif signifikan terhadap kinerja karyawan. Yang artinya semakin bagus budaya organisasi maka semakin meningkatkan kinerja karyakan. Namun penelitian tersebut bertolak belakang dengan penelitian Laswitarni (2010); Fajra (2011) yang menemukan hasil berbeda dimana budaya organisasi memberikan dampak negatif terhadap kinerja karyawan. Berdasarkan kesenjangan penelitian (research gap) yang diperoleh dari hasil penelitian sebelumnya, maka penelitian ini mencoba mengatasi kesenjangan tersebut melalui peran variabel kepuasan kerja sebagai mediator antara locus of control dan Budaya Organisasi Terhadap Kinerja Karyawan.

\section{METODE PENELITIAN}

Penelitian ini menggunakan jenis data primer yang diperoleh melalui penyebaran kuesioner terhadap Tenaga Pendidik di MTsN 1 Andalan, MTsN 2 dan MTsN 3 Kota Pekanbaru. Instumen penelitian yang diberikan kepada responden dalam bentuk kuesioner dilakukan dengan teknik skala likert 5 poin untuk mengukur variabel penelitian. Responden nantinya memilih jawaban dari pernyataan positif dengan 5 alternatif jawaban yang ada, yaitu "Sangat Setuju (SS), Setuju (S), Ragu- ragu (RR), Tidak Setuju (TS), Sangat Tidak Setuju (STS)"

Populasi dalam penelitian ini adalah seluruh tenaga kependidikan yang berjumlah 111 orang guru. Pengambilan sampel dilakukan dengan metode senus dimana alasannya adalah jumlah populasi penelitian tidak terlalu besar. Oleh itu jumlah sampel yang di ambil adalah 132 orang guru

Untuk menganalisa model dan hipotesis yang akan menjawab pertanyaan penelitian, maka dilakukan analisis dengan menggunakan software SmartPLS versi 3.2.8. Uji Partial Least Square (PLS) merupakan pendekatan persamaan 
struktrural (Structural Equation Modelling/SEM) berbasis varian. Dalam pengujian SEM-PLS dilakukan dengan dua tahapan yaitu analisa Model Pengukuran (Outer Model) dan Analisis Model Struktural (Inner Model). Berikut merupakan model penelitian yang dikembangkan dalam penelitian ini :

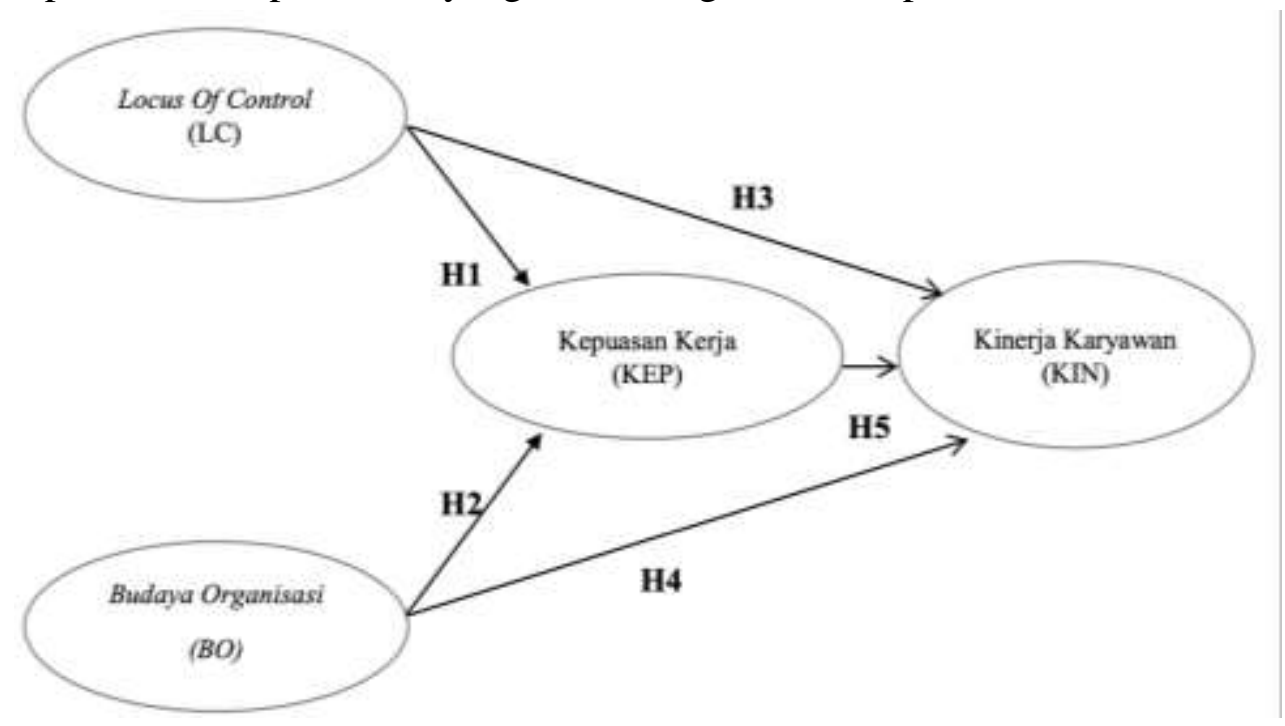

Gambar 1. Model Penelitian

Model penelitian di atas, dijelaskan melalui hipotesis berikut :

H1 : Locus of Control memberikan pengaruh positif terhadap peningkatan kepuasan Kerja Guru.

$\mathrm{H} 2$ : Locus of Control memberikan pengaruh terhadap peningkatan Kinerja Guru

H3 : Budaya Organisasi memberikan pengaruh signifikan terhadap peningkatan kepuasan Guru

H4 : Budaya Organisasi memberikan pengaruh signifikan terhadap peningkatan kinerja Guru

H5 : Kepuasan Kerja memberikan pengaruh signifikan terhadap peningkatan kinerja Guru

\section{HASIL PENELITIAN}

\section{Analisa Demografi Responden}

Berikut merupakan hasil analisa demografi responden dalam penelitian ini

Tabel 1. Data Demografi Responden

\begin{tabular}{llll}
\hline & Demografi & Jumlah & Persentase \\
\hline \multirow{2}{*}{ Institusi } & MTsN 1 Pekanbaru & 40 & $36.0 \%$ \\
\cline { 2 - 4 } & MTsN 2 Pekanbaru & 25 & $22.5 \%$ \\
\cline { 2 - 4 } & MTsN 3 Pekanbaru & 46 & $41.4 \%$ \\
\hline \multirow{2}{*}{ Total } & & $\mathbf{1 1 1}$ & $\mathbf{1 0 0} \%$ \\
\hline \multirow{2}{*}{ Jenis Kelamin } & Laki-laki & 27 & $24.3 \%$ \\
\cline { 2 - 4 } & Perempuan & 84 & $75.7 \%$ \\
\hline Usia & Total & $\mathbf{1 1 1}$ & $\mathbf{1 0 0} \%$ \\
\hline
\end{tabular}




\begin{tabular}{llll}
\hline & $30-40$ tahun & 37 & $33.3 \%$ \\
\hline \multirow{2}{*}{ Total } & & 29 & $26.1 \%$ \\
\hline \multirow{2}{*}{$\begin{array}{l}\text { Pendidikan } \\
\text { terakhir }\end{array}$} & $\mathrm{S} 1$ & $\mathbf{1 1 1}$ & $\mathbf{1 0 0} \%$ \\
\cline { 2 - 4 } & $\mathrm{S} 2$ & 94 & $84.7 \%$ \\
\cline { 2 - 4 } & $\mathrm{S} 3$ & 16 & $14.4 \%$ \\
\hline Total & & 1 & $0.9 \%$ \\
\hline Masa Kerja & $>10$ Tahun & $\mathbf{1 1 1}$ & $\mathbf{1 0 0} \%$ \\
\cline { 2 - 4 } & 1-5 Tahun & 51 & $45.9 \%$ \\
\cline { 2 - 4 } & 5-10 Tahun & 19 & $36.1 \%$ \\
\hline Total & & $\mathbf{1 1 1}$ & $\mathbf{1 0 0} \%$ \\
\hline
\end{tabular}

Sumber : Data Olahan SPSS (2021)

Berdasarkan data di atas dapat dijelaskan bahwa sebaran guru MTsN di Pekanbaru yang menjadi responden dalam penelitian ini mayoritas terdiri dari perempuan sebesar $75.7 \%$ dan berusaia kurang dari 30 tahun sebanyak $40.5 \%$. Untuk tingkat pendidikan guru rata-rata guru berpendidikan S1 sebanak 84.7\%, di ikuti dengan pendidikan S2 sebanyak $14.4 \%$ dan S3 sebanyak 0.9\%. Terakhir, masa kerja guru dalam penelitian ini di dominasi oleh guru bermasa kerja lebih dari 10 tahun sebanyak $49.5 \%$.

\section{Hasil Uji Validitas dan Reliabilitas}

Untuk mengetahui keabsahan alat ukur yang di gunakan, maka dilakukan uji validitas dan reliabilitas terhadap 30 orang responden (pilot tes), hasil uji validitas dan reliabilitas diperoleh hasil sebagai berikut :

Tabel 2. Hasil Uji Validitas dan Reliabilitas

\begin{tabular}{|c|c|c|c|}
\hline Variabel & Pernyataan & $\begin{array}{c}\text { Corrected Item-Total } \\
\text { Correlation }\end{array}$ & Cronbach Alpha \\
\hline \multirow{6}{*}{ Locus of Control } & LC1 & .560 & \multirow{6}{*}{0.824} \\
\hline & $\mathrm{LC} 2$ & .627 & \\
\hline & LC3 & .525 & \\
\hline & LC4 & .564 & \\
\hline & LC8 & .577 & \\
\hline & LC9 & .759 & \\
\hline \multirow{5}{*}{ Budaya Organisasi } & $\mathrm{BO} 2$ & .808 & \multirow{5}{*}{0.930} \\
\hline & $\mathrm{BO} 3$ & .824 & \\
\hline & $\mathrm{BO} 4$ & .690 & \\
\hline & BO5 & .901 & \\
\hline & BO6 & .869 & \\
\hline \multirow{6}{*}{ Kepuasan } & KEP1 & .335 & \multirow{6}{*}{0.703} \\
\hline & KEP3 & .536 & \\
\hline & KEP4 & .418 & \\
\hline & KEP5 & .417 & \\
\hline & KEP6 & .423 & \\
\hline & KEP9 & .520 & \\
\hline \multirow{5}{*}{ Kinerja Karyawan } & KIN1 & .622 & \multirow{5}{*}{0.931} \\
\hline & KIN2 & .409 & \\
\hline & KIN3 & .730 & \\
\hline & KIN4 & .764 & \\
\hline & KIN5 & .700 & \\
\hline
\end{tabular}




\begin{tabular}{|c|c|c|c|}
\hline Variabel & Pernyataan & $\begin{array}{c}\text { Corrected Item-Total } \\
\text { Correlation }\end{array}$ & Cronbach Alpha \\
\hline & KIN6 & .721 & \\
\hline & KIN7 & .879 & \\
\hline & KIN8 & .819 & \\
\hline & KIN9 & .394 & \\
\hline & KIN11 & .383 & \\
\hline & KIN12 & .583 & \\
\hline & KIN13 & .591 & \\
\hline & KIN14 & .474 & \\
\hline & KIN15 & .802 & \\
\hline & KIN16 & .425 & \\
\hline & KIN17 & .388 & \\
\hline & KIN18 & .774 & \\
\hline & KIN20 & .859 & \\
\hline & KIN21 & .608 & \\
\hline
\end{tabular}

Sumber : Data Olahan SPSS (2021)

\section{Hasil uji SEM PLS}

\section{Convergent Validity}

Convergent Validity adalah model pengukuran dengan indikator refleksif berdasarkan korelasi antara skor item dan skor komponen dengan PLS. Nilai factor loading hanya melihat hubungan antar indikator dengan konstruk eksogen. Nilai loading faktor yang < 0,5 harus dikeluarkan dari model dan dilakukan estimasi ulang nilai factor loading. Dengan mengeluarkan beberapa nilai loading faktor < 0,5 maka telah diperoleh nilai loading faktor yang telah di estimasi sebagai berikut :

Tabel 3. Loading Factor

\begin{tabular}{|c|c|c|}
\hline Variabel & Pernyataan & Loading Factor \\
\hline \multirow{6}{*}{ Locus of Control } & $\mathrm{LC} 1$ & 0.736 \\
\hline & $\mathrm{LC} 2$ & 0.741 \\
\hline & LC3 & 0.744 \\
\hline & LC4 & 0.595 \\
\hline & LC8 & 0.664 \\
\hline & LC9 & 0.872 \\
\hline \multirow{4}{*}{ Budaya Organisasi } & $\mathrm{BO} 3$ & 0.529 \\
\hline & $\mathrm{BO} 4$ & 0.864 \\
\hline & $\mathrm{BO} 5$ & 0.951 \\
\hline & BO6 & 0.830 \\
\hline \multirow{5}{*}{ Kepuasan } & KEP1 & 0.632 \\
\hline & KEP3 & 0.590 \\
\hline & KEP4 & 0.543 \\
\hline & KEP6 & 0.720 \\
\hline & KEP9 & 0.757 \\
\hline \multirow{7}{*}{ Kinerja Karyawan } & KIN1 & 0.679 \\
\hline & KIN3 & 0.800 \\
\hline & KIN4 & 0.793 \\
\hline & KIN5 & 0.749 \\
\hline & KIN6 & 0.808 \\
\hline & KIN7 & 0.843 \\
\hline & KIN8 & 0.873 \\
\hline
\end{tabular}




\begin{tabular}{lcc}
\hline Variabel & Pernyataan & Loading Factor \\
\hline KIN12 & 0.644 \\
\cline { 2 - 3 } & KIN13 & 0.670 \\
\cline { 2 - 3 } & KIN14 & 0.593 \\
\cline { 2 - 3 } & KIN15 & 0.815 \\
\hline KIN18 & 0.786 \\
\hline KIN20 & 0.863 \\
\hline & KIN21 & 0.725 \\
\hline
\end{tabular}

Sumber : Data Olahan SPSS (2021)

Berdasarlan tabel di atas, dapat dilihat bahwa hasilnya telah memenuhi convergant validity karena semua factor loading $>0.5$. Dengan demikian, dapat disimpulkan convergant validity dari seluruh kelompok konstruk endogen adalah valid.

\section{Discriminant Validity}

Model dikatakan mempunyai discriminant validity yang baik jika setiap nilai loading indikator dari sebuah variabel laten lebih besar berkorelasi dengan variabel laten tersebut dibanding bila dikorelasikan dengan variabel laten lainnya.

Tabel 4. Cross Loading

\begin{tabular}{|c|c|c|c|c|c|}
\hline Variabel & Indikator & $\begin{array}{c}\text { Budaya } \\
\text { Organisasi }\end{array}$ & Kepuasan & Kinerja & $\begin{array}{l}\text { Locus of } \\
\text { Control }\end{array}$ \\
\hline \multirow{4}{*}{$\begin{array}{l}\text { Budaya } \\
\text { Organisasi }\end{array}$} & $\mathrm{BO} 3$ & 0.529 & 0.177 & -0.192 & -0.176 \\
\hline & BO4 & 0.864 & 0.167 & -0.460 & -0.466 \\
\hline & BO5 & 0.951 & 0.357 & -0.389 & -0.509 \\
\hline & BO6 & 0.830 & 0.125 & -0.285 & -0.456 \\
\hline \multirow[t]{6}{*}{ Kepuasan } & KEP1 & 0.260 & 0.632 & 0.282 & 0.164 \\
\hline & KEP3 & 0.173 & 0.590 & -0.069 & 0.098 \\
\hline & KEP4 & 0.308 & 0.543 & 0.143 & -0.046 \\
\hline & KEP6 & 0.095 & 0.720 & 0.137 & 0.381 \\
\hline & KEP9 & 0.128 & 0.757 & 0.165 & 0.392 \\
\hline & KIN1 & -0.095 & 0.257 & 0.679 & 0.485 \\
\hline \multirow[t]{11}{*}{ Kinerja } & KIN12 & -0.209 & 0.205 & 0.644 & 0.477 \\
\hline & KIN13 & -0.242 & 0.288 & 0.670 & 0.385 \\
\hline & KIN14 & -0.331 & 0.194 & 0.593 & 0.557 \\
\hline & KIN15 & -0.340 & 0.127 & 0.815 & 0.561 \\
\hline & KIN18 & -0.193 & 0.293 & 0.786 & 0.620 \\
\hline & KIN20 & -0.225 & 0.300 & 0.863 & 0.690 \\
\hline & KIN21 & -0.001 & 0.484 & 0.725 & 0.650 \\
\hline & KIN3 & -0.549 & 0.082 & 0.800 & 0.690 \\
\hline & KIN4 & -0.416 & 0.021 & 0.793 & 0.492 \\
\hline & KIN5 & -0.571 & -0.060 & 0.749 & 0.411 \\
\hline & KIN6 & -0.599 & 0.071 & 0.808 & 0.711 \\
\hline
\end{tabular}




\begin{tabular}{llrrrr}
\hline Variabel & Indikator & $\begin{array}{c}\text { Budaya } \\
\text { Organisasi }\end{array}$ & Kepuasan & Kinerja & \multicolumn{1}{c}{$\begin{array}{c}\text { Locus of } \\
\text { Control }\end{array}$} \\
\hline \multirow{4}{*}{$\begin{array}{l}\text { Locus of } \\
\text { Control }\end{array}$} & KIN7 & -0.320 & 0.085 & 0.843 & 0.583 \\
\cline { 2 - 6 } & KIN8 & -0.441 & 0.155 & 0.873 & 0.733 \\
\cline { 2 - 6 } & LC2 & -0.626 & 0.079 & 0.482 & 0.741 \\
\cline { 2 - 6 } & LC3 & -0.608 & 0.018 & 0.843 & 0.744 \\
\cline { 2 - 6 } & LC4 & -0.135 & 0.507 & 0.121 & 0.595 \\
\cline { 2 - 6 } & LC8 & -0.286 & 0.449 & 0.400 & 0.664 \\
\cline { 2 - 6 } & LC9 & -0.400 & 0.391 & 0.642 & 0.872 \\
\cline { 2 - 6 } & LC1 & -0.149 & 0.294 & 0.616 & 0.736 \\
\hline
\end{tabular}

Sumber : Data Olahan SPSS (2021)

Berdasarkan Tabel nilai loading factor untuk setiap indikator dari masingmasing variabel laten memiliki nilai loading factor yang paling besar dibanding nilai loading factor jika dihubungkan dengan variabel laten lainnya. Hal ini berarti bahwa setiap variabel laten memiliki discriminant validity yang baik.

\section{Uji Reliabilitas}

Tahapan selanjutnya adalah pengujian konsitensi pengukuran (reliabilitas) dengan Average Variance Extract (AVE) dan Composite Realiability (CR). Reliabilitas tinggi menunjukkan bahwa indikator-indikator mempunyai konsistensi tinggi dalam mengukur konstruk latennya (Wijayanto, 2008). Reliabilitas dapat diketahui melalui nilai Composite Reliability (CR) dan Average Variance Extracted (AVE). Composite reliability dikatakan baik bila memiliki nilai $\geq 0.7$. Nilai AVE dikatakan baik bila memiliki nilai $\geq 0.5$ (Ghazali, 2009). Data hasil pengujian AVE dan CR ditunjukkan pada tabel 5 berikut ini.

Tabel 5. Reliabilitas Konstruk

\begin{tabular}{lrrrr}
\hline \multicolumn{1}{c}{ Variabel } & $\begin{array}{c}\text { Cronbach's } \\
\text { Alpha }\end{array}$ & rho_A & $\begin{array}{c}\text { Composite } \\
\text { Reliability }\end{array}$ & $\begin{array}{c}\text { Average Variance } \\
\text { Extracted (AVE) }\end{array}$ \\
\hline Budaya Organisasi & 0.811 & 0.894 & 0.879 & 0.655 \\
\hline Kepuasan & 0.679 & 0.689 & 0.786 & 0.527 \\
\hline Kinerja & 0.944 & 0.952 & 0.951 & 0.585 \\
\hline Locus of Control & 0.827 & 0.850 & 0.871 & 0.533 \\
\hline Sumber : Data Olahan SPSS (2021) & & &
\end{tabular}

Berdasarkan hasil uji validitas dan reliabilitas dari model pengukuran, dapat disimpulkan bahwa semua variable teramati valid mengukur variabel latennya, dan realiabilitas model pengukurannya pun baik. Hal ini menunjukkan bahwa indikator reliable dalam menyusun konstruk eksogen. 


\section{Pengujian Model Struktural (Inner Model)}

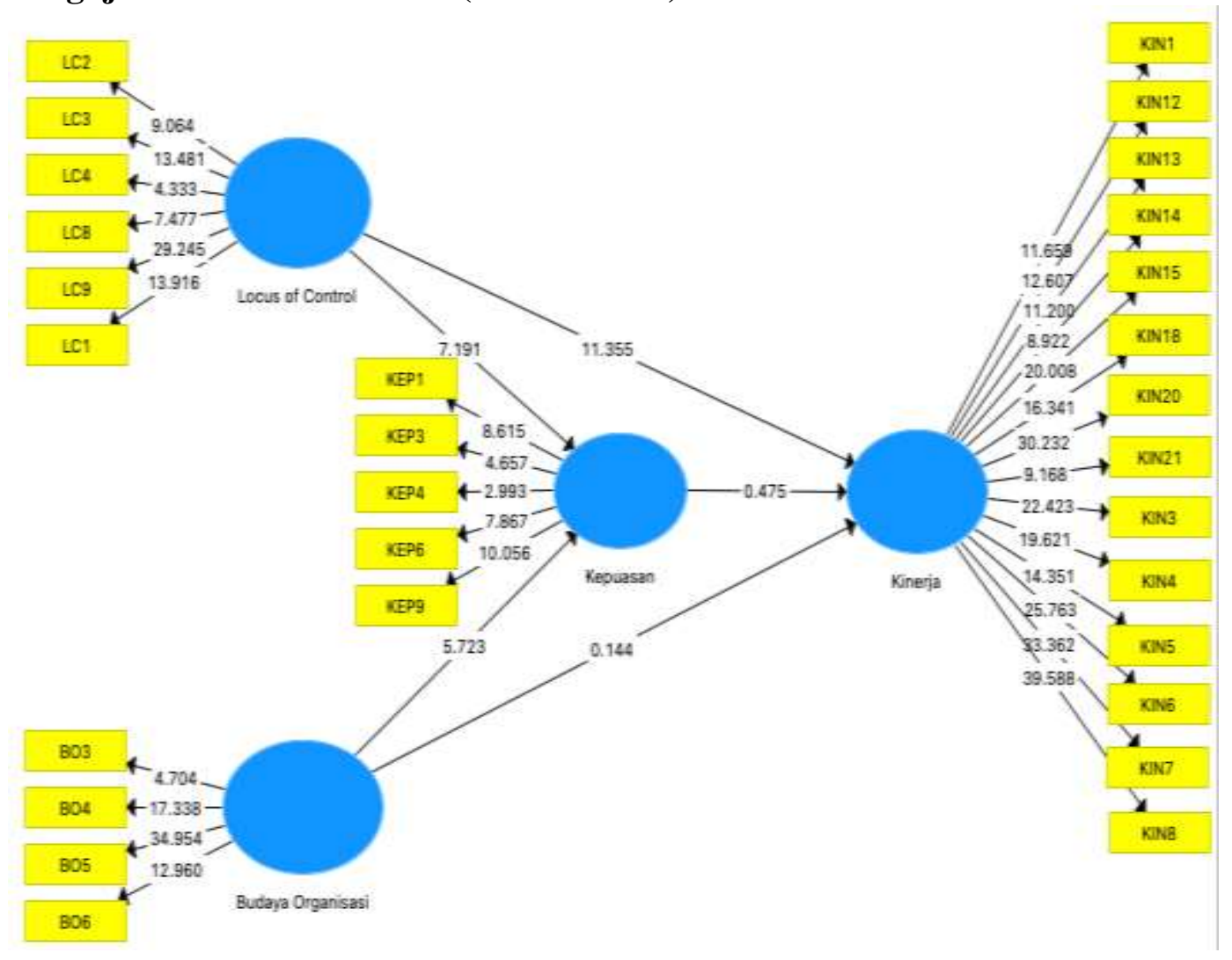

Gambar 2. Model penelitian (inner model)

Tabel 6. Pengujian R Square

\begin{tabular}{ccc}
\hline Variabel & R Square & R Square Adjusted \\
\hline Kepuasan & 0.417 & 0.406 \\
\hline Kinerja & 0.600 & 0.589 \\
\hline Sumber : Data Olahan SPSS (2021) &
\end{tabular}

Berdasarkan Tabel nilai adjusted R-square untuk variabel Kinerja sebesar 0.589. Hal ini berarti bahwa variabel Kinerja dijelaskan oleh variabel Budaya Organisasi, Locus of Control dan kepuasan kerja sebesar $58.9 \%$. Sedangkan nilai Rsquare untuk variabel Kepuasan sebesar 0.406 yang berarti bahwa variabel Kepuasan Kerja dijelaskan oleh Budaya Organisasi dan Locus of Control sebesar $40.6 \%$. 


\section{Pengujian Hipotesis}

Berikut merupakan hasil uji hipotesis :

Tabel 7. Koefisien Path

\begin{tabular}{ccccccc}
\hline & $\begin{array}{c}\text { Original } \\
\text { Sample } \\
(\mathbf{O})\end{array}$ & $\begin{array}{c}\text { Sample } \\
\text { Mean } \\
(\mathbf{M})\end{array}$ & $\begin{array}{c}\text { Standard } \\
\text { Deviation } \\
(\text { STDEV })\end{array}$ & $\begin{array}{c}\text { T Statistics } \\
(|\mathbf{O} / \mathbf{S T D E V}|)\end{array}$ & P Values & Ket \\
\hline $\begin{array}{c}\text { Locus of Control -> } \\
\text { Kepuasan }\end{array}$ & 0.686 & 0.687 & 0.095 & 7.191 & 0.000 & Diterima \\
\hline $\begin{array}{c}\text { Locus of Control -> } \\
\text { Kinerja }\end{array}$ & 0.783 & 0.794 & 0.069 & 11.355 & 0.000 & Diterima \\
\hline $\begin{array}{c}\text { Budaya Organisasi - } \\
\text { > Kepuasan }\end{array}$ & 0.625 & 0.626 & 0.109 & 5.723 & 0.000 & Diterima \\
\hline $\begin{array}{c}\text { Budaya Organisasi - } \\
\text { > Kinerja }\end{array}$ & -0.012 & -0.025 & 0.084 & 0.144 & 0.885 & Ditolak \\
\hline $\begin{array}{c}\text { Kepuasan -> } \\
\text { Kinerja }\end{array}$ & -0.047 & -0.051 & 0.098 & 0.475 & 0.635 & Ditolak \\
\hline Sumber : Data Olahan SPSS $(\mathbf{2 0 2 1})$ & & & &
\end{tabular}

Sumber : Data Olahan SPSS (2021)

Berdasarkan tabel di atas maka hipotesis penelitian yang diperoleh adalah sebagai berikut :

H1 : Dari hasil analisa statistik hasil uji T menunjukkan angka sebesar $7.191>\mathrm{T}$ tabel 1.67 dan nilai P Value menunjukkan perolehan $0.000<\alpha 0.05$ (dengan koefisien $\mathrm{O}$ positif), maka dapat disimpulkan $\mathrm{H} 1$ diterima dan artinya terdapat pengaruh pengaruh positif Locus of Control terhadap peningkatan kepuasan kerja guru.

$\mathrm{H} 2$ : Dari hasil analisa statistik hasil uji T menunjukkan angka sebesar $11.355>\mathrm{T}$ tabel 1.67 dan nilai P Value menunjukkan perolehan $0.000<\alpha 0.05$ (dengan koefisien $\mathrm{O}$ positif), maka dapat disimpulkan $\mathrm{H} 2$ diterima dan artinya terdapat pengaruh positif Locus of Control terhadap peningkatan Kinerja Guru.

H3 :. Dari hasil analisa statistik hasil uji T menunjukkan angka sebesar $5.723>\mathrm{T}$ tabel 1.67 dan nilai P Value menunjukkan perolehan $0.000<\alpha 0.05$ (dengan koefisien $\mathrm{O}$ positif), maka dapat disimpulkan $\mathrm{H} 3$ diterima dan artinya terdapat pengaruh positif budaya organisasi terhadap peningkatan kepuasan Guru.

H4 :. Dari hasil analisa statistik hasil uji T menunjukkan angka sebesar $0.144<\mathrm{T}$ tabel 1.67 dan nilai P Value menunjukkan perolehan $0.885>\alpha 0.05$ (dengan koefisien $\mathrm{O}$ negatif), maka dapat disimpulkan $\mathrm{H} 4$ ditolak dan artinya tidak terdapat pengaruh pengaruh positif budaya organisasi terhadap peningkatan kinerja Guru.

H5 : Dari hasil analisa statistik hasil uji T menunjukkan angka sebesar $0.475<\mathrm{T}$ tabel 1.67 dan nilai P Value menunjukkan perolehan $0.635>\alpha 0.05$ (dengan koefisien $\mathrm{O}$ negatif), maka dapat disimpulkan $\mathrm{H} 4$ ditolak dan artinya tidak terdapat pengaruh pengaruh positif kepuasan terhadap peningkatan kinerja Guru . 


\section{PEMBAHASAN}

Dari hasil analisa statistik hasil uji $\mathrm{T}$ menunjukkan $\mathrm{H} 1$ dan $\mathrm{H} 2$ diterima dan artinya terdapat pengaruh pengaruh positif Locus of Control terhadap peningkatan kepuasan Kerja dan kinerja Guru. Dengan demikian, hal ini bermakna peningkatan terhadap locus of control guru dapat pula meningkatkan kepuasan guru dalam bekerja. Dalam pentingnya aspek locus of control yang harus di teliti dalam individu tenaga pengajar di madrasah, karena control diri merupakan poin penting dalam berinteraksi serta menyampaikan suatu pelayanan kepada orang lain terutama peserta didik. hal ini di dukung oleh mayoritas guru dalam penelitian ini yang sudah memiliki pendidikan sarjana, hal ini berarti semakin tinggi pendidikan sesorang maka pengaturan terhadap diri akan menjadi lebih baik. Hasil penelitian ini sejalan dengan penelitian Amalini, et al. (2016); Adi, et al. (2012); Nainggolan et al., (2018) berhasil membuktikan bahwa locus of control berpengaruh positif signifikan terhadap kepuasan kerja karyawan. selain berdampak terhadap kepuasan guru, locus of control juga memberikan dampak terhadap kinerja guru yang mana hasil penelitian ini juga sejalan dengan penelitian yang dilakukan oleh Putri (2015) karyawan yang memiliki locus of control yang tinggi akan lebih mudah puas terhadap pekerjaannya yang nantinya akan turut meningkatkan kinerja.

Hasil penelitian menunjukkan bahwa untuk variabel budaya organisasi pada H3 diterima sedangkan untuk H4 di tolak. yang artinya budaya organisasi memiliki pengaruh positif signifikan terhadap kepuasan kerja namun tidak terhadap kinerja guru. budaya organisasi merupakan suatu falsafah nilai dan keyakinan dari suatu kebiasaan bersamayang kemudian menghasilkan normanorma sebagai pedoman perilaku/tindakan dan cara berfikir dalam upaya pencapaian tujuan bersama. Dalam penelitian ini, ramainya guru yang telah memiliki masa kerja lebih dari 10 tahun seharusnya menunjukkan bahwa budaya organisasi telah terbentuk dengan sendirinya sehingga mampu mendatangkan kepuasan dan kenyamanan dalam bekerja. Namun di sisi lain, penelitian juga menunjukkan bahwa budaya organisasi bukan satu-satunya penentu dalam peningkatan kinerja guru yang mungkin lebih di pengaruhi oleh variabel lain. Hasil penelitian ini bertolak belakang dengan penelitian Kusuma \& Rahardja (2018); Hasan (2017); Cahyono (2012); Arianty (2015) budaya organisasi memiliki pengaruh positif signifikan terhadap kinerja karyawan.

Hasil penelitian pada hipotesis 5 menunjukkan bahwa kepuasan kerja tidak berpengaruh positif signifikan terhadap kinerja guru. Kepuasan kerja merupakan suatu sikap emosianal yang ditunjukkan melalui rasa senang dan cinta terhadap suatu pekerjaan. Dalam penelitian ini kepuasan kerja bukan menjadi satu-satunya penentu terhadap kinerja guru. Oleh karena itu penelitian ini sejalan dengan penelitian Kuswoyo, et al. (2018); Amalini, et al. (2016) kepuasan kerja tidak berpengaruh signifikan terhadap kinerja karyawan melainkan dipengaruh oleh faktor-faktor lainnya. 


\section{SIMPULAN}

Locus of control yang dimiliki oleh guru memberikan pengaruh positif signifikan terhadap kepuasan kerja dan juga kinerja guru. Selain itu, budaya organisasi juga mendukung terhadap peningkatan kepuasan kerja guru yang artinya semakin baik budaya organisasi, maka semakin meningkat kepuasan guru, dan juga sebaliknya. Namun, hal ini tidak berlaku dalam meningkatkan kinerja. hasil peneltiian menunjukkan bahwa budaya organisasi tidak memiliki pengaruh positif signifikan terhadap peningkatan kinerja guru. Hasil pengujian hipotesis terakhir menunjukkan bahwa kepuasan kerja tidak berpengaruh positif signifikan terhadap kinerja guru.

\section{DAFTAR PUSTAKA}

Adi, K., Saputra, K., \& Ganesha, U. P. (2012). Pengaruh Locus of Control terhadap Kinerja dan Kepuasan Kerja Internal Auditor dengan Moderasi. Jurnal Akuntansi Multiparadigma, 3(1), 1-160.

Arianty, N. (2015). Pengaruh Budaya Organisasi terhadap Kinerja Pegawai Rumah Sakit Haji Medan. Tesis

Amalini, H. F., Musadieq, M. Al, Afrianty, T. W., Administrasi, F. I., \& Brawijaya, U. (2016). Pengaruh Locus of Control terhadap Kepuasan Kerja dan Kinerja (Studi Pada Karyawan Perusahaan Daerah Air Minum ( PDAM ) Kota Malang ). Jurnal Administrasi Bisnis, 35(1), 68-77.

Aulia, N., Indarti, S., \& Efni, Y. (2017). Pengaruh Budaya Organisasi dan Motivasi kerja terhadap Kepuasan Kerja dan Kinerja Karyawan pada PT Bank Tabungan Negara (Persero) Tbk. Cabang Pekanbaru. Jurnal Manajemen, 5(2), 235-250.

Cahyono, A. (2012). Analisa Pengaruh Kepemimpinan, Motivasi dan Budaya Organisasi terhadap Kinerja Dosen dan Karyawan di Universitas Pawyatan Daha Kediri. Tesis.

Fajra, F. K. (2011). Pengaruh Gaya Kepemimpinan, Budaya Organisasi, dan Motivasi Kerja terhadap Kinerja Karyawan Badan Kepegawaian Daerah Kabupaten Agam. Skripsi.

Hasibuan, M. S. . (2017). Manajemen Sumber Daya Manusia Edisi Revisi. Jakarta: Bumi Aksara.

Hastuti, W. dan M. F. (2015). Motivasi, Internal Locus of Control dan Kepuasan Kerja pada Karyawan Bagian Marketing dan Supporting di PT X Cabang Surabaya. Jurnal Psikologi Indonesia, 4(2), 195-207.

Hasan, S. (2017). Pengaruh Budaya Organisasi terhadap Kinerja Pegawai Bank BJB Cabang Banjarmasin. 3(2),238-242.

Husein, U. (2010). Riset Pemasaran dan Perilaku Konsumen. Jakarta: Gramedia Pustaka Utama.

Hellriegel \& Slocum. (2011). Organizational Behavior 13th edition. USA: SouthWestern Cengange Learning.

Hermawan, F., \& Kaban, D. F. (2014). Pengaruh Locus of Control terhadap Kinerja Karyawan ( Studi Pada Karyawan Di PT X ). Manajemen \& Bisnis, 5(1), 32-39. 
Kuswoyo, Komara, A. H., \& Junaedi, A. T. (2018). Pengaruh Gaya Kepemimpinan Organisasi Serta Motivasi Kerja terhadap Kepuasan Kerja dan Kinerja Guru Sekolah Dasar di Kecamatan Rimba Melintang. Procuratio, 6(4), 360-372.

Kusuma, G., \& Rahardja, E. (2018). Pengaruh Gaya Kepemimpinan Transformasional, Budaya Organisasi dan Motivasi Kerja terhadap Kinerja Karyawan. Diponegoro Jurnal Of Management, 7(2), 11.

Laswitarni, N. K. (2010). Pengaruh Budaya Organisasi, Kepuasan Kerja dan Motivasi Terhadap Kinerja Karyawan PT.Delta Satria Dewata Denpasar.

Nainggolan,Mian Admiral, C. K. dan G. S. (2018). Analisis Pengaruh Internal Locus of Control dan External Locus of Control terhadap Kepuasan Kerja Serta Dampaknya terhadap Kinerja Tenaga Kependidikan di Fakultas Ekonomi dan Bisnis Universitas Sam Ratulangi. Jurnal EMBA, 6(4), 4023-4032.

Putri, N. M. D. R. (2015). Analisis Perbedaan Tingkat Kepuasan Kerja Auditor Pada Locus of Control Internal dan Eksternal. Jurnal Akuntansi Universitas Udayana, 13(1), 68-83.

Shirly, D. (2018). Pengaruh Motivasi dan Disiplin Kerja terhadap Kepuasan Kerja dan Kinerja Karyawan di PT. Bank Central Asia, Tbk. Kantor Cabang Utama Pekanbaru. Jurnal Procuratio, 6(3), 259-271.

Umam, K. (2010). Perilaku Organisasi. Bandung: Pustaka Setia.

Zulkaida, A. (2007). Pengaruh Locus of Control dan Efikasi Diri terhadap Kematangan Karir Siswa Sekolah Menengah Atas ( SMA ). Proceeding Pesat, 2(2), 21-22. 